\title{
Planejamento de rede logística de produtos agrícolas orgânicos: agrupamento de unidades em arranjos produtivos locais como estratégia para redução do custo logístico
}

\author{
Adelaida Pallavicini Fonseca'; Paulo Pessoa Guerra Neto²; Edwin Pinto de la Sota Silva ${ }^{3}$
}

\begin{abstract}
Resumo: O setor agrícola Brasileiro encontra-se em expansão, tornando-se um dos principais contribuintes do aumento do crescimento do PIB nacional e participação ativa na economia mundial. No entanto, a produção agrícola e agropecuária encontra na infraestrutura logística física seu principal desafio, já que tem que procurar soluções para os problemas de escoamento da produção. Este problema soma-se à falta de planejamento estratégico das cadeias de suprimento, de produção e distribuição, e essencialmente ao problema de planejamento de redes logísticas. Para contribuir na solução deste problema, este trabalho desenvolveu um modelo de planejamento do sistema logístico de distribuição para o setor hortigranjeiro de produtos orgânicos. O modelo propõe a criação de um banco de dados para diagnosticar a situação deáreas de estudos e simular cenários alternativos de redes logísticas, tendo como principais variáveis de decisão: o agrupamento de unidades produtivas, as características de veículos e localizações de pontos de venda alternativos.
\end{abstract}

\begin{abstract}
The Brazilian agricultural sector is under enlargement, becoming one of the main contributors to the growth of national GDP as well active involvement in the worldwide economy. However, the logistic physical infrastructure is the main endeavor for the agricultural and farming production since it's necessary to find solutions for the problems related to production delivery. This problem must be considered in addition to the lack of strategic planning of supply chains, of production and distribution, and mainly to the problem of logistics networks planning. In order to assist the solution of this problem, this study developed a model for the planning of logistic distribution system to the produce sector for organic products. This model suggests the creation of a database to diagnose the condition of study areas and simulate alternative logistic network scenarios, having as the main variables decision: the grouping of productive units, vehicle characteristics and the location of alternative selling spots.
\end{abstract}

\section{INTRODUÇÃO}

O planejamento, assim como a configuração da rede logística de distribuição e comercialização de produtos agropecuários, principalmente daqueles que provém da agricultura familiar, muitas vezes, deriva em sérios problemas por causa da inexperiência e do conhecimento empírico dos produtores rurais, que, muitas vezes, por questões culturais consideram o planejamento estratégico dispensável. Esses fatores somados aos problemas de cooperativismo e inexperiências gerenciais dos pequenos e médios produtores influenciam em seus canais de comercialização e nas negociações com as principais redes de vendas de produtos agrícolas. Como resultado, eles terminam comercializando seus próprios produtos sem contar com as devidas estruturas administrativa, logístico-operacional e física, incidindo dessa forma na competitividade, atratividade e preços de seus produtos.

Dentre os problemas mais relevantes identificados

\footnotetext{
${ }^{1}$ Adelaida Pallavicini Fonseca, Programa de Pós-Graduação em Transportes, Universidade de Brasília, Brasília, DF, Brasil. (e-mail: ixcanil@unb.br).

${ }^{2}$ Paulo Pessoa Guerra Neto, Programa de Pós-Graduação em Transportes, Universidade de Brasília, Brasília, DF, Brasil. (e-mail: pguerra@unb.br).

${ }^{3}$ Edwin Pinto de la Sota Silva, Programa de Pós-Graduação em Agronegócios, Universidade de Brasília, Brasília, DF, Brasil. (e-mail: delasota@unb.br).
}

Manuscrito recebido em 21/5/2010 e aprovado para publicação em $11 / 8 / 2010$. Este artigo é parte de TRANSPORTES, volume XVIII, número 3, setembro de 2010. ISSN: 2237-1346 (online). na rede logística de distribuição e de comercialização dos produtos agrícolas, principalmente os orgânicos, tem-se: utilização de veículos impróprios para a movimentação dos produtos, em geral, carrocerias abertas; má acomodação dos produtos na caçamba dos veículos; problemas de gestão para lidar com a oferta sazonal de produtos; carência de postos de vendas estáveis para atender aos clientes; falta de articulação, de negociação e de racionalização dos recursos e outros.

Procurar novos mercados para comercializar a produção se torna cada vez mais difícil devido à complexidade dos mercados, exigências dos consumidores e dificuldade de implantar uma infraestrutura logística que movimente rapidamente os produtos ao mínimo custo ao longo da rede logística. A estruturação da rede logística de distribuição é um desafio para os especialistas, pois demanda a integração de diversas funções principais e secundárias da logística, assim como, do sistema produtivo de forma a oferecer um determinado nível de serviço ao menor custo. Assim, se para os gerentes de logística das empresas de grande porte este é uma meta a ser alcançada para manter a competitividade no acirrado mundo dos negócios, qual é a dimensão do problema para os pequenos e médios produtores, que não tem a mesma capacidade de gerenciamento?

O problema é ainda maior quando se considera o caso de núcleos de produtores de produtos orgânicos formados por famílias de pequeno e médio porte com foco na agricultura de subsistência que comercializa o 
excedente da produção nos mercados locais e regionais. Estes mercados são as feiras populares com endereço em locais públicos que atendem em dias específicos da semana. A rede de distribuição e comercialização é sempre ajustada quando um novo produtor passa a participar do grupo ou outro local passa a ser utilizado como ponto de venda. A delimitação da área de abrangência do mercado onde atuam estes produtores depende apenas dos objetivos e dos recursos disponíveis. Uma das principais características deste tipo de agricultores é a comercialização de produtos orgânicos para determinados nichos de mercados, que atendem consumidores seletos tanto na condição sóciocultural como econômica. Ou seja, são pessoas esclarecidas em relação ao poder nutritivo desses legumes, vegetais e frutas cultivadas da forma mais natural, capazes de pagar além do preço dos produtos não orgânicos tradicionalmente comercializados nas feiras, mercados e outros.

Atualmente, as grandes redes de supermercados estão investindo forte para dar maior visibilidade a esses produtos nas gôndolas, com o intuito de atrair consumidores novos e fidelizá-los, situação que incide nas redes de negócios das associações de agricultores que operam independentes destes, já que eles não têm como competir com as estratégias de marketing fortes e agressivas dos supermercados. Essa situação se torna difícil à medida que a condição sócio-cultural dos agricultores é baixa e o grau de gestão das propriedades ainda é muito empírico.

Dos resultados das pesquisas realizadas junto aos agricultores e associações pode-se perceber que as associações de agricultores orgânicos enfrentam três grandes desafios (Guerra, 2005).

- O primeiro desafio consiste em identificar esses segmentos de mercado, de forma a definir canais de distribuição que lhes permitam colocar seus produtos nas prateleiras do mercado ao mínimo custo, oferecendo um bom nível de serviço ao consumidor;

- O segundo desafio está em determinar um plano estratégico de ação para poder enfrentar de forma competitiva a concorrência das redes de supermercados. Alguns desses supermercados possuem fazendas próprias, enquanto outros mantêm parcerias com associações de agricultores que abastecem diretamente suas gôndolas. Neste caso, o agricultor é o elo da cadeia de suprimentos da rede de supermercado, onde sua função é exclusivamente produzir;

- O terceiro desafio consiste, em como a associação deve se organizar e articular para potencializar sua capacidade de planejar e gerenciar, assim, em como definir planos de investimentos para estruturar, implementar e operar sua pró- pria rede de distribuição e de negócios.

A rigor, conclui-se que é urgente a necessidade de planejamento da rede logística de distribuição das associações que cultivam produtos orgânicos, buscando definir políticas estratégicas que ajudem a impulsionar o setor. Diante deste quadro, procurou-se formular um modelo que sirva de referência às associações de agricultores orgânicos para realizar o planejamento da rede logística de distribuição. Assim, este trabalho vem contribuir com o desenvolvimento de um modelo que dá subsídios no planejamento de uma rede logística de distribuição, contemplando a demanda potencial de mercado e as possibilidades econômicas dos produtores de produtos orgânicos.

\section{PLANEJAMENTO DA REDE LOGÍSTICA}

O problema de configuração da rede logística é essencial nos objetivos de uma empresa, estando no topo da lista dos assuntos de planejamento, já que permite uma melhoria no serviço ao cliente e na competitividade da empresa, uma vez que é possível gerar economias (Ballou,2001; Bowersox, 2001). A configuração da rede logística diz respeito à escolha de parceiros e às funções atribuídas a estes dentro de uma cadeia de suprimentos (Van Der Vorst, 2000).Assim, as relações entre os participantes da rede não é constante e pode ser mudada rapidamente, pois cada elemento possui propósitos específicos e tempo de uso finito. Nesse sentido, a rede logística é a representação físico-espacial dos pontos de origens e destino das mercadorias, bem como de seus fluxos e demais aspectos relevantes de forma a possibilitar a visualização do sistema logístico em um dado período do tempo.

A modelagem da rede logística pode ser definida como uma metodologia que busca aperfeiçoar um determinado objetivo e aumentar a eficiência e eficácia operacional de uma empresa, facilitando o planejamento e a gestão da rede de instalações logísticas e seus respectivos fluxos. A configuração dos pontos de origens e destinos depende das características operacionais de cada empresa, do seu negócio e dos seus canais de distribuição.

Uma rede sofre influência de várias estruturas, como os processos de negócios, sistemas de informação, regras de suporte à decisão e a colaboração entre os participantes da cadeia. Alguns princípios são básicos para reduzir as chances de uma cadeia de suprimento ser mal desenhada ou estruturada. Dentre elas pode-se citar (Muckstadtet. al., 2001): conhecer o consumidor; desenhar uma cadeia de suprimento que elimine o desperdício, a variabilidade e as incertezas; criar uma infra-estrutura de informações concisa entre os parceiros da cadeia; entrelaçar os processos entre as firmas 
participantes; compartilhar o uso de sistemas de apoio de decisão.

O desenho da rede logística pode ser feito de várias formas e descrita por quatro elementos (Jack, Van Der Vorst e Beulens, 2002): configuração física da rede; estrutura de controle da rede; sistemas de informação da rede e; estrutura organizacional da rede. Uma rede de distribuição otimizada é de grande importância para o desempenho logístico e rentabilidade da empresa. Apesar disto, os estudos relacionados à configuração da rede normalmente tratam somente os casos de empresas manufatureiras, deixando de lado as redes de produtos agrícolas onde os recursos são mais escassos e as técnicas administrativas e gerenciais se encontram mais atrasados.

Um dos maiores problemas relacionados ao gerenciamento e controle de redes logísticas são as incertezas intrínsecas a alguns tipos de cadeias de suprimento. A incerteza, quando propagada pela cadeia, gera processos ineficientes e atividades que não adicionam valor ao produto final. Normalmente, pode-se expressar a incerteza a partir de certas perguntas, como (Jack, Van Der Vorst e Beulens, 2002): o que o consumidor vai comprar?; quantos produtos deve-se ter em estoque?; será que o fornecedor vai entregar o produto na hora certa e nas condições combinadas?

A incerteza estimula os tomadores de decisão a criar zonas de amortecimento no tempo, na capacidade e/ou no estoque que previnem as baixas performances da cadeia de suprimento. Estas zonas restringem o desempenho operacional diminuindo a vantagem competitiva. Quanto maior for a incerteza em uma rede maior serão os desperdícios de recursos ao longo dela. É possível caracterizar as fontes de incertezas em três categorias: características inerentes à rede, características da rede e fenômenos exógenos (Jack, Van Der Vorst e Beulens, 2002). A primeira categoria, características inerentes à rede, refere-se as que causam flutuações com padrão estocástico de ocorrência. A incerteza, neste caso ocorre devido à alta variabilidade da demanda, dos processos ou do suprimento. A segunda categoria provém das características da rede, que resultam em distúrbios no desempenho do sistema, por exemplo, instalações inflexíveis (configuração da rede), decisões aplicadas erroneamente (estrutura de controle), demora na troca de informação (sistema de informação) ou má interpretação por parte dos tomadores de decisão (estrutura organizacional). A terceira categoria trata dos fenômenos externos à cadeia que perturbam o sistema, como as mudanças nos mercados, produtos, tecnologias, concorrentes e regulamentação governamental.

\section{ESTUDOS LOGÍSTICOS APLICADOS AO SETOR AGRÍCOLA ORGÂNICO}

No setor agrícola, de maneira geral, são poucos os estudos realizados nas cadeias produtivas, assim como sobre as maneiras de escoamento da produção entre a propriedade e os pontos de venda. Há material técnico elaborado por empresas governamentais como a EMATER, EMBRAPA e nas entidades certificadoras de produtos orgânicos, como o Instituto Biodinâmico (IBD). Nas revistas e jornais é comum ler artigos e reportagens que argumentam como a falta de recursos neste setor implica na perda de milhões de reais na comercialização dos produtos tanto no mercado interno quanto para a exportação.

Apesar da cadeia hortifrutigranjeira ser importante para a economia do país não existem muitos trabalhos desenvolvidos nesta área, que carece de recursos e estudos para melhoria de seu desempenho. Além disto, o desenvolvimento da cadeia de produtos orgânicos somente interessou aos produtores há menos de uma década, quando observaram a mudança cultural do consumo de alimentos saudáveis.

\section{MODELO PARA O PLANEJAMENTO DO SISTEMA LOGÍSTICO DE DISTRIBUIÇÃO}

O modelo proposto para o planejamento da rede logística de produtores do setor hortigranjeiro pode ser sintetizado na Figura 1. O modelo proposto foi concebido no conhecimento do setor hortigranjeiro, identificando as principais variáveis que precisam ser estudadas e os dados necessários para alimentar as diferentes rotinas ou fases do modelo. A idéia principal e inicial da proposta era desenvolver um sistema computacional integrado e interativo que permitisse implementar e testar o modelo de planejamento da rede logística interagindo com os resultados parciais das diferentes rotinas do modelo. No entanto, devido à necessidade de utilizar determinados softwares e aplicativos - como o ARCVIEW, o MAP OBJECTS, o CRIMESTAT e o LINGO - como ferramentas de apoio para resolver diversas rotinas do modelo proposto, então se decidiu por trabalhar as rotinas de forma separada. Com o objetivo de testar o modelo proposto foi feito um estudo de caso no Distrito Federal.

\subsection{Caracterização da cadeia produtiva dos produtores orgânicos do Distrito Federal}

No Distrito Federal a produção é consumida na própria região (80\%) enquanto que o resto é comercializado em outras cidades do Brasil ou exportado para outros países. Do consumido internamente, a minoria é vendida no atacado ou em supermercados, enquanto que no varejo, as feiras populares são a principal forma de comercialização, seguida pela venda em lojas especializadas e, por último, venda direta na unidade 


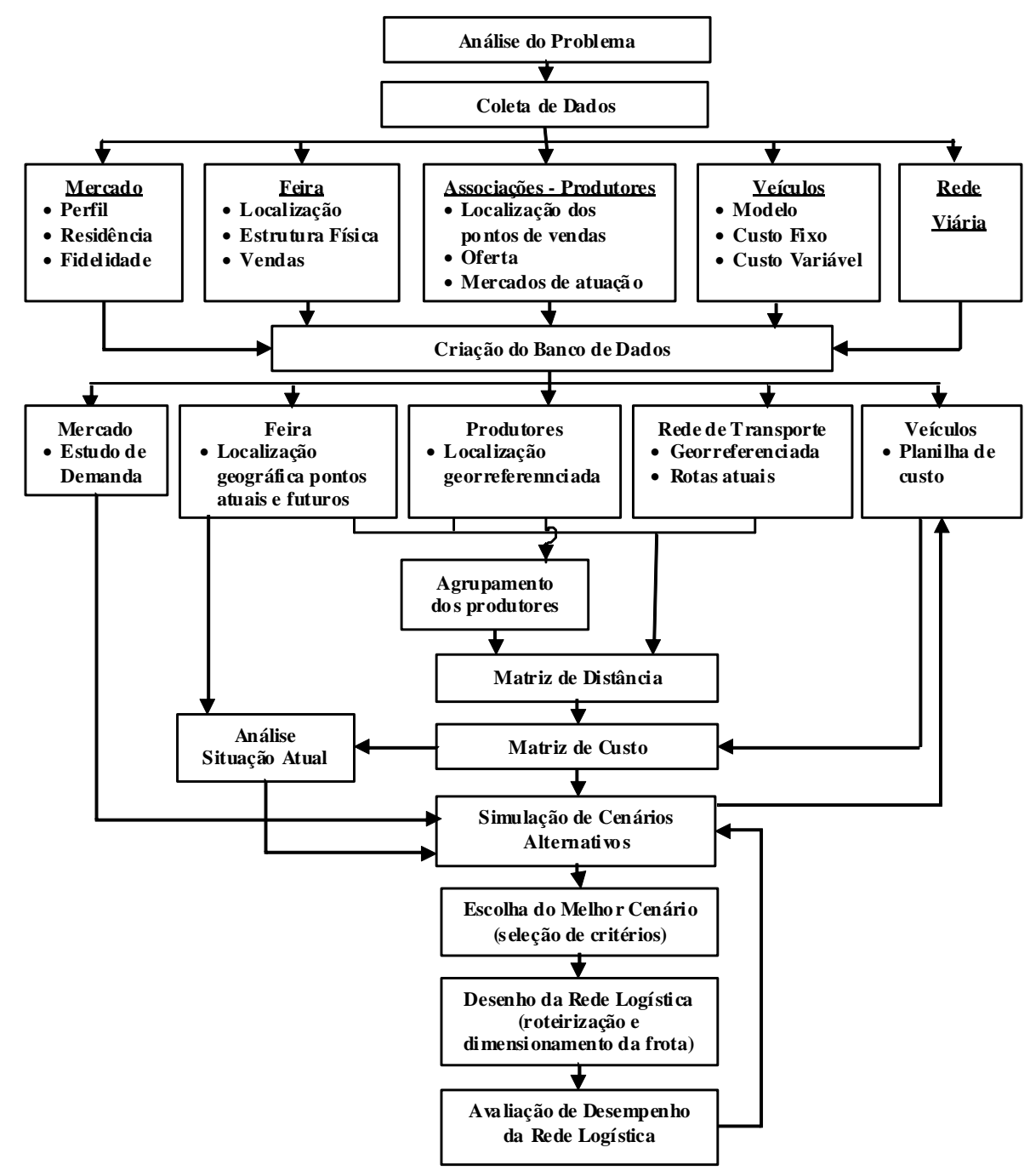

Figura 1. Heurística de análise de redes de transporte hortigranjeiro

produtora. Da análise realizada no mercado varejista do Distrito Federal observaram-se graves problemas nas feiras populares onde se comercializa $65 \%$ da produção. Sendo assim, procurou-se estudar as feiras com maior volume de vendas e com maior período histórico, necessário para determinar a demanda média mais próxima da realidade.

As duas associações escolhidas para analisar os problemas de distribuição e comercialização foram identificadas no estudo como Associação de Agricultura Ecológica (AAGE) e o Mercado Orgânico (MO). A AAGE possui sede no sindicato rural do Distrito Federal e conta com 11 membros em sua composição. Sua marca já está consolidada no Brasil, visto que foi uma das primeiras a serem fundadas, há 16 anos. Já o MO é mais recente e surgiu da necessidade de organizar os produtores que participavam da feira no estacionamento do CEASA. Essa associação ainda não possui sede e normalmente se reúne na sede do EMATER-DF ou na feira semanal. A grande vantagem desta associação é que está localizada estrategicamente em um local de grande movimentação de pessoas e produtos hortifrutigranjeiros. A marca cria- da por estes produtores está crescendo e chega a atrair novos compradores semanalmente. Em ambas as associações, os custos relativos ao aluguel e limpeza do espaço são divididos entre todos os participantes.

\subsection{Análise do mercado varejista do Distrito Federal}

A análise do mercado varejista do Distrito Federal foi dividida em três fases. A primeira fase consistiu em levantar os dados das quatro principais feiras populares do DF, localizadas: a) no estacionamento do CEASA; b) no estacionamento da quadra 112 Sul; c) na sede do sindicato rural, 909 sul; d) e no estacionamento da Igreja Messiânica do DF, 315 Norte. Verificou-se que todas as feiras funcionam aos sábados pela manhã, já que a baixa freqüência semanal não justifica a utilização de um endereço comercial específico. Normalmente, os espaços aproveitados são estacionamentos, que durante os sábados ficam ociosos.

A segunda fase da análise foi definir, por meio de entrevista, as características dos consumidores de produtos orgânicos, obtendo-se as seguintes informações: os consumidores têm alto poder econômico;eles estão bem informados sobre as qualidades dos produtos or- 
gânicos e de seus efeitos benéficos; são moradores de regiões urbanas; a idade média destes consumidores varia entre 30 e 60 anos; são freqüentadores regulares e fieis das feiras populares de hortifrutigranjeiros e frutas, visto que mais de $75 \%$ dos entrevistados declararam que a freqüentam semanalmente.

A terceira fase do trabalho consistiu em esquematizar a atual rede de distribuição, identificando os principais gargalos do sistema logístico-produtivo de ambas as associações. Estes são: fazendas pequenas com capacidade limitada de produção; uma grande variedade de produtos (mix) orgânicos ofertados, porém em baixa quantidade; pulverização das fazendas, muito espalhadas pela região e as vezes bem separadas entre si; feiras localizadas distantes das unidades produtivas; infra-estrutura limitada para operações logísticoprodutivas no processo de distribuição, incluindo atividades de colheita, limpeza, consolidação e embalagem, manuseio, carga e descarga, entre outras; falta de coordenação e otimização do transporte fazendafazenda e fazenda-feira; falta de uma unidade de marketing; e outros problemas de ordem administrativofinanceiros.

\subsection{Coleta e criação do banco de dados}

Foram realizadas cinco pesquisas de campo com o propósito de alimentar o banco de dados proposto na metodologia.

\subsubsection{Dados dos produtores}

A pesquisa junto aos próprios agricultores rurais mereceu muita atenção. O questionário elaborado com- preendeu os seguintes itens: nome; nome da propriedade; tamanho da propriedade; área certificada; produtos plantados; quantidade produzida; região administrativa; veículo utilizado para o transporte da carga. De acordo com a filosofia da agricultura orgânica, a multiplicidade de espécies no cultivo favorece o equilíbrio dos recursos naturais, por isso cada produtor procura plantar uma grande variedade de produtos para conseguir esse equilíbrio. Assim, quantificar a produção total se torna uma tarefa complexa, já que cada produto possui pesos e tamanhos específicos, dificultando sua padronização em uma única unidade de medida. Para resolver este problema, utilizou-se como unidade padrão de medida a caixa de plástico com as medidas de $60 \mathrm{~cm} \times 40 \mathrm{~cm} \times 50 \mathrm{~cm}$, pois são utilizadas por todos os produtores em suas unidades de produção. Cada qual marca sua caixa pela cor ou pelo seu nome gravado na lateral.O levantamento do número de caixas foi feito junto aos produtores em um período de 16 semanas seguidas. Os resultados obtidos se encontram na Tabela 1.

\subsubsection{Dados das feiras}

Na pesquisa realizada junto às feiras foram levantadas informações sobre a demanda, perfil dos consumidores e características dos produtores que fornecem produtos nestes locais de venda. Na questão estrutural, as feiras são constituídas por gôndolas metálicas cobertas por uma lona branca montada em uma estrutura de fácil armação. A estimativa da demanda (vendas) pelos produtos orgânicos comercializados nas feiras foi feita com auxílio dos próprios produtores. A Tabela 1 deta-

Tabela 1. Produção de produtos orgânicos das associações AAGE e MO e demanda média semanal de produtos por feira em número de caixas

\begin{tabular}{|c|c|c|c|c|c|c|c|}
\hline \multirow{2}{*}{ Identificador } & \multirow{2}{*}{ Nome da chácara } & \multirow{2}{*}{ Associação } & \multirow{2}{*}{$\begin{array}{c}\text { PRODUÇÃO } \\
\text { Total de } \\
\text { caixas }\end{array}$} & \multicolumn{4}{|c|}{$\begin{array}{c}\text { VENDAS } \\
\text { (número de caixas) }\end{array}$} \\
\hline & & & & CEASA & $\begin{array}{l}909 \\
\text { Sul }\end{array}$ & $\begin{array}{l}112 \\
\text { Sul }\end{array}$ & $\begin{array}{c}316 \\
\text { Norte }\end{array}$ \\
\hline Z01 & Chácara Santa Cecília & $\mathrm{MO}$ & 30 & 24 & 0 & 0 & 0 \\
\hline Z02 & Sítio Geranium & MO & 114 & 12 & 41 & 0 & 49 \\
\hline Z03 & Recanto Rural & MO & 30 & 29 & 0 & 0 & 0 \\
\hline Z04 & Chácara Oliveira & MO & 10 & 9 & 0 & 0 & 0 \\
\hline Z05 & Crismarino & AAGE & 44 & 0 & 14 & 26 & 0 \\
\hline Z06 & Sítio Conquista & AAGE/ MO & 33 & 30 & 0 & 0 & 0 \\
\hline $\mathrm{Z} 07$ & Chácara Barbosa & AAGE & 25 & 0 & 0 & 22 & 0 \\
\hline Z08 & Chácara $54^{\mathrm{a}}$ & AAGE & 7 & 0 & 0 & 7 & 0 \\
\hline Z09 & Horta Viva & AAGE & 8 & 2 & 0 & 5 & 0 \\
\hline $\mathrm{Z} 10$ & Sítio Alegria & AAGE & 55 & 8 & 18 & 0 & 26 \\
\hline Z11 & Chácara Portal & MO & 12 & 11 & 0 & 0 & 0 \\
\hline $\mathrm{Z} 12$ & Sítio Colina & AAGE & 24 & 0 & 10 & 0 & 11 \\
\hline Z13 & Sítio Frutos da Terra & $\mathrm{MO}$ & 65 & 60 & 0 & 0 & 0 \\
\hline Z14 & Chácara TAO & $\mathrm{MO}$ & 40 & 35 & 0 & 0 & 0 \\
\hline Z15 & Fazenda Jacaré & MO & 8 & 7 & 0 & 0 & 0 \\
\hline Z16 & Fazenda Malunga & AAGE & 258 & 42 & 95 & 0 & 110 \\
\hline \multirow[t]{2}{*}{$\mathrm{Z} 17$} & Chácara Nakamura & MO & 75 & 70 & 0 & 0 & 0 \\
\hline & Total & & & 339 & 178 & 60 & 196 \\
\hline
\end{tabular}


lha as vendas semanais (demanda cativa) de produtos orgânicos nas feiras, onde são comercializados ao todo aproximadamente 776 caixas de plástico.

\subsubsection{Localização dos produtores e feiras orgânicas}

A localização dos produtores e das feiras foi realizada com auxílio de um aparelho receptor de GPS. O levantamento das coordenadas das feiras foi efetuado mais rapidamente, pois todas as feiras estudadas se encontram na área urbana. Quanto aos produtores, o levantamento das informações foi feito após visita nas unidades produtoras, o que demandou mais tempo.

\subsubsection{Dados da rede viária}

O banco de dados utilizado para registrar a rede viária teve como referencia o mapa digital do Distrito Federal da Companhia de Desenvolvimento do Planalto Central - CODEPLAN. Com este arquivo pode-se trabalhar com a extensão de leitura de arquivos CAD do programa ArcView. A partir desta base foi possível acrescentar e editar as vias que formam parte da rede viária da região de estudo, assim como identificar aquelas utilizadas pelos produtores para realizar as entregas nas feiras, observando que as características destas vias são similares. Além disso, não existem quase caminhos alternativos entre as fazendas e as feiras.

\subsubsection{Dados dos veículos}

São 16 tipos de veículos diferentes usados para o transporte de produtos hortigranjeiros. Quatro (4) são carros de passeio (considerado qualquer veículo de carga com características urbanas de pequeno porte), oito (8) são caminhonetes e/ou utilitários pequenos (kombi),e quatro (4) são caminhões leves (caminhão toco com capacidade aproximada de 7 toneladas). Dos 17 produtores, 11 utilizam seus próprios veículos e seis (6) produtores, todos da região de Brazlândia, compartilham o serviço terceirizado de um caminhão leve.

\subsection{Matriz de distância}

A matriz de distância (formada pela rota viária de menor distância entre os diversos pontos de origem e destino) é uma das rotinas do modelo desenvolvida em linguagem de programação Visual Basic ${ }^{\circledR}$. O componente MapObjects $^{\mathrm{TM}}$, da empresa ESRI, que realiza a edição de mapas e objetos georreferenciados foi adicionado à rotina computacional.No cálculo da matriz de distância não se incluiu o percurso interno de coleta dos produtos nas unidades.

\subsection{Matriz de custos}

Para estudar os custos de transporte selecionaram-se seis (6) tipos de veículos existentes no mercado, similares aos que são usados pelos produtores da região de estudo, não considerando os carros de passeios. Os cálculos destes foram levantados para estudar a situação atual. A referência para o cálculo dos custos foi feita em base a informações extraídas do site Economia e Transportes (2009). Com os dados dos seis (6) tipos de veículos e a matriz de distância estruturaramse as matrizes de custos.

\subsection{Análise da situação atual}

A matriz atual de entrega foi montada para representar o fluxo dos produtos orgânicos no Distrito Federal até as feiras de consumo espalhadas pela cidade. Dentre os principais problemas detectados estão: dispersão espacial dos produtores orgânicos; entrega direta até as feiras; utilização das mesmas rotas de viagens e; utilização de veículos impróprios para o transporte. Dessa forma, ao final do dia de feira, todos os produtores percorrem 1.326,85 quilômetros, a um custo total de $\mathrm{R} \$ 1.498,48$. Ao ano, os custos de entrega dos

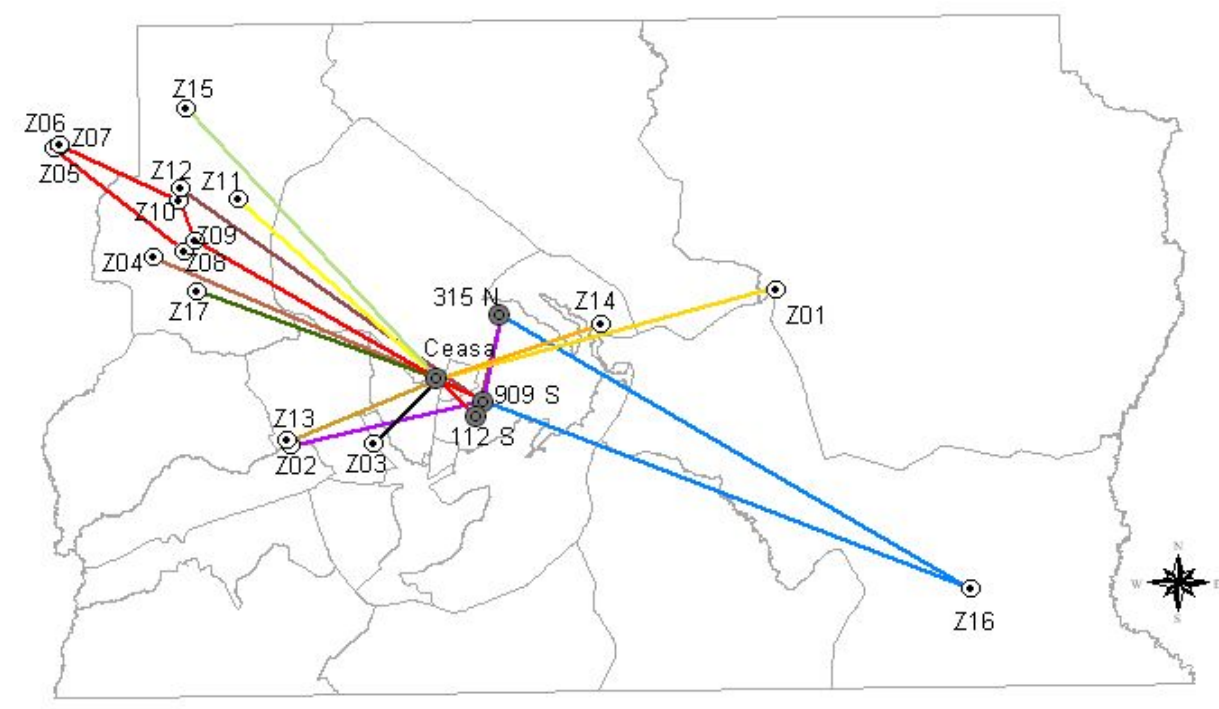

Figura 2. Configuração da rede logística atual 
produtos orgânicos nas feiras podem alcançar $\mathrm{R}$ \$ $82.500,00$.

\subsection{Agrupamento dos produtores}

Essa análise foi realizada utilizando o programa CRIMESTAT ${ }^{\circledR}$ (programa livre), do tipo "standalone”, ou seja, não é necessário instalar componentes na máquina do usuário. Neste trabalho foi escolhida a técnica do agrupamento hierárquico do vizinho mais próximo (NearestNeighborHierarchicalClustering $N n h)$. Os clusters formados são apenas indicações dos locais de alta concentração de pontos, que no caso representam as unidades produtivas orgânicas. Após a formação dos grupos, realizou-se uma análise, visando equilibrá-los. Ao todo foram criados 7 clusters, que possuem desde 1 até 4 produtores.

\subsection{Simulação de cenários alternativos e escolha do melhor cenário}

Como pode ser observado, este é um tipo de problema de análise combinatória, onde o processo consistiu em combinar todos os clusters com todas as feiras, sendo que cada uma destas combinações precisou ser combinada com todos os diferentes tipos de veículos utilizados no transporte dos hortifrutigranjeiros orgânicos, assim, foram geradas inúmeras possibilidades. O programa escolhido para resolver este problema foi o LINGO de Pesquisa Operacional.

Os valores da função objetivo dos cenários gerados no LINGO mostraram grandes diferenças, onde o menor valor foi aproximadamente 4 vezes menor que o maior.Dessa forma, somente foram selecionados dois cenários que tiveram valores próximos e cabíveis de serem analisados, os outros foram descartados.Definiu-se, então, o critério final de escolha do cenário ótimo como sendo aquele que tivesse a maior taxamédia de oferta de produtos absorvidos nas feiras e não excluísse do cenário nenhum grupo de produtores.

O Cenário 2 foi o que apresentou a maior taxa média de caixas entregues por cluster, 94\%., sendo que todos os produtores ficaram com suas entregas garantidas.Como a produção dos clusters 4 e 7 é grande se- rá necessário utilizar dois (2) caminhões para executar a distribuição física, entretanto, no caso dos clusters 5 e 6, como apresentaram altas taxas de ociosidade do veículo utilizado, pode-se trabalhar com um veículo de capacidade menor.

O Cenário 1 apresentou resultados piores que o Cenário 2, pois teve uma taxa média de entrega mais baixa, além de ter violado um dos critérios de escolha. No cluster 6 não houve entrega de produtos e no cluster 5 a previsão de comercialização foi de somente 12,5\% do total produzido.Portanto, o cenário escolhido foi o 2, uma vez que a média de entrega nas feiras é maior que o Cenário 1, além de possuir o menor valor da função objetivo.Na análise constatou-se que a demanda de todas as feiras foram supridas, ao mesmo tempo em que, com exceção do cluster 7 onde sobraram 65 unidades para serem consumidas, todos os outros agrupamentos tiveram sua produção total escoada para o consumo.

\section{DESENHO DA REDE LOGÍSTICA E AVALIAÇÃO DE DESEMPENHO}

Nesta etapa do processo, com base no cenário escolhido se definiram os caminhos a serem percorridos pelos veículos, incluindo a rota de coleta dentro de cada agrupamento (cluster), assim como a frota total a ser utilizada. O veículo selecionado no Cenário 2 foi um caminhão leve, MB 710 Plus Baú, com capacidade para 160 caixas.

Na Tabela 2 resumem-se os resultados da rede proposta. A coluna caminho externo representa a movimentação desde as unidades produtivas para carregar as caixas de plástico até as feiras selecionadas para esse agrupamento (cluster), incluindo o percurso de volta até as unidades produtoras. A coluna caminho interno é o deslocamento que realiza o veículo entre os produtores que formam o agrupamento, quando o valor é zero, somente tem-se um produtor.

A distância total a ser percorrida pela frota em um dia de feira será aproximadamente de $830 \mathrm{~km}$ a um custo total de $\mathrm{R} \$ 876,67$, considerando um veículo por agrupamento, ou seja, um total de sete (7) veícu-

Tabela 2. Custo total de distribuição da carga nos sábados

\begin{tabular}{|c|c|c|c|c|c|c|c|}
\hline Cluster & $\begin{array}{c}\text { Produção } \\
\text { (número de caixas) }\end{array}$ & Feiras & $\begin{array}{c}\text { Caminho } \\
\text { Externo } \\
(\mathrm{km} .) \\
\end{array}$ & $\begin{array}{c}\text { Caminho } \\
\text { Interno } \\
(\mathrm{km} .) \\
\end{array}$ & Total & $\begin{array}{c}\text { MB } 710 \\
\text { Plus Baú } \\
\text { R\$ / Km }\end{array}$ & $R \boldsymbol{S}$ \\
\hline CL01 & 110 & CEASA & 115,03 & 37,46 & 152,49 & 1,06 & 161,63 \\
\hline CL02 & 91 & 315 NORTE & 102,97 & 41,51 & 144,48 & 1,06 & 153,14 \\
\hline CL03 & 100 & CEASA -112 SUL & 84,5 & 37,55 & 122,05 & 1,06 & 129,37 \\
\hline CL04 & 209 & CEASA & 35,78 & 24,92 & 60,7 & 1,06 & 64,34 \\
\hline CL05 & 40 & 112 SUL & 43,44 & 0 & 43,44 & 1,06 & 46,04 \\
\hline CL06 & 30 & 909 SUL & 145,42 & 0 & 145,42 & 1,06 & 154,14 \\
\hline CL07 & 258 & 315 NORTE & 158,47 & 0 & 158,47 & 1,06 & 167,97 \\
\hline & & & \multicolumn{2}{|c|}{ Total } & 827,05 & Total & 876,67 \\
\hline
\end{tabular}


los.Como já observado, os agrupamentos 4 e 7 necessitarão de dois (2) caminhões para realizar a entrega nas feiras, pois suas ofertas passam o limite de carga do veículo. Para evitar capacidade ociosa do segundo veículo a ser usado pelo agrupamento 7 é proposto que este veículo faça a coleta de caixas nos agrupamentos 5 e 6 , já que as feiras destinos estão na mesma rota. Fazendo esse rearranjo, o total de veículos propostosfica novamente em sete (7). Com relação à distancia total percorrida e os custos, estes permanecem quase iguais que os da Tabela 2 . O resultado gráfico da nova rede logística se mostra na Figura 3.

A nova proposta de configuração da rede logística dos produtores orgânicos do Distrito Federal se mostrou mais econômica que a situação atual. Conforme descrito no item 4.6, o custo total de entrega no cenário atual é de $\mathrm{R} \$ 1.498,48$, enquanto que os valores encontrados pela análise do melhor cenário (cenário 2) chegou a um custo de distribuição de $\mathrm{R} \$ 876,67$. A diferença entre o cenário atual e o proposto é de R\$ 622,48, ou seja, 57\% menor que a situação atual. Após um ano, se alcançaria uma economia de $\mathrm{R} \$ 34.236,40$, valor que pode ser investido em melhorias na infra-estrutura das associações. Dessa forma, a proposta da nova rede logística criada com auxílio do modelo proposto se mostrou mais vantajosa, podendo economizar recursos financeiros e aumentar sua força no mercado varejista interno.

\section{CONCLUSÃO}

O mercado de produtos orgânicos vem se desenvolvendo de forma rápida em todo o mundo. Observa-se que o Brasil participa com um grande número de uni- dades produtoras e pela grande quantidade de produtos exportados, percebe-se a dualidade criada entre 0 produto exportado e aquele consumido internamente. Enquanto as cadeias logísticas de exportação se encontram estruturadas, uma vez que são planejadas por grandes atores econômicos mundiais, os canais utilizados no mercado interno ainda se encontram em estágio de desenvolvimento, pois os produtores que comercializam seus produtos neste mercado estão em um processo de aprendizado e conhecimento de técnicas gerenciais.

Sendo assim, dentre as inúmeras possibilidades de estudo nesta área, este trabalho abrangeu alguns componentes essenciais à análise das cadeias logísticas do setor hortifrutigranjeiro de subsistência, levantando a urgente necessidade de criação de um modelo para a resolução dos problemas logísticos reais enfrentados pelas associações de produtores orgânicos. A contribuição deste trabalho teve caráter cientifico e social, uma vez que cientificamente foi desenvolvida uma heurística de configuração da rede logística de grupos de produtores. O trabalho também possibilita uma melhoria das condições de trabalho e aumento da possibilidade de receita pela diminuição dos custos de transporte na coleta e distribuição física de produtos.

O modelo desenvolvido permite fazer um diagnostico da situação real, levantar os dados necessários para a realização do planejamento e utilizar as técnicas de criação de agrupamentos e de programação linear para simular cenários alternativos, possibilitando fazer a escolha do melhor cenário. Sobre este cenário pode-se desenhar a rede logística do sistema sob estudo. As ferramentas de criação de agrupamento e de Pesquisa Operacional utilizadas no trabalho mostraram-se efici-

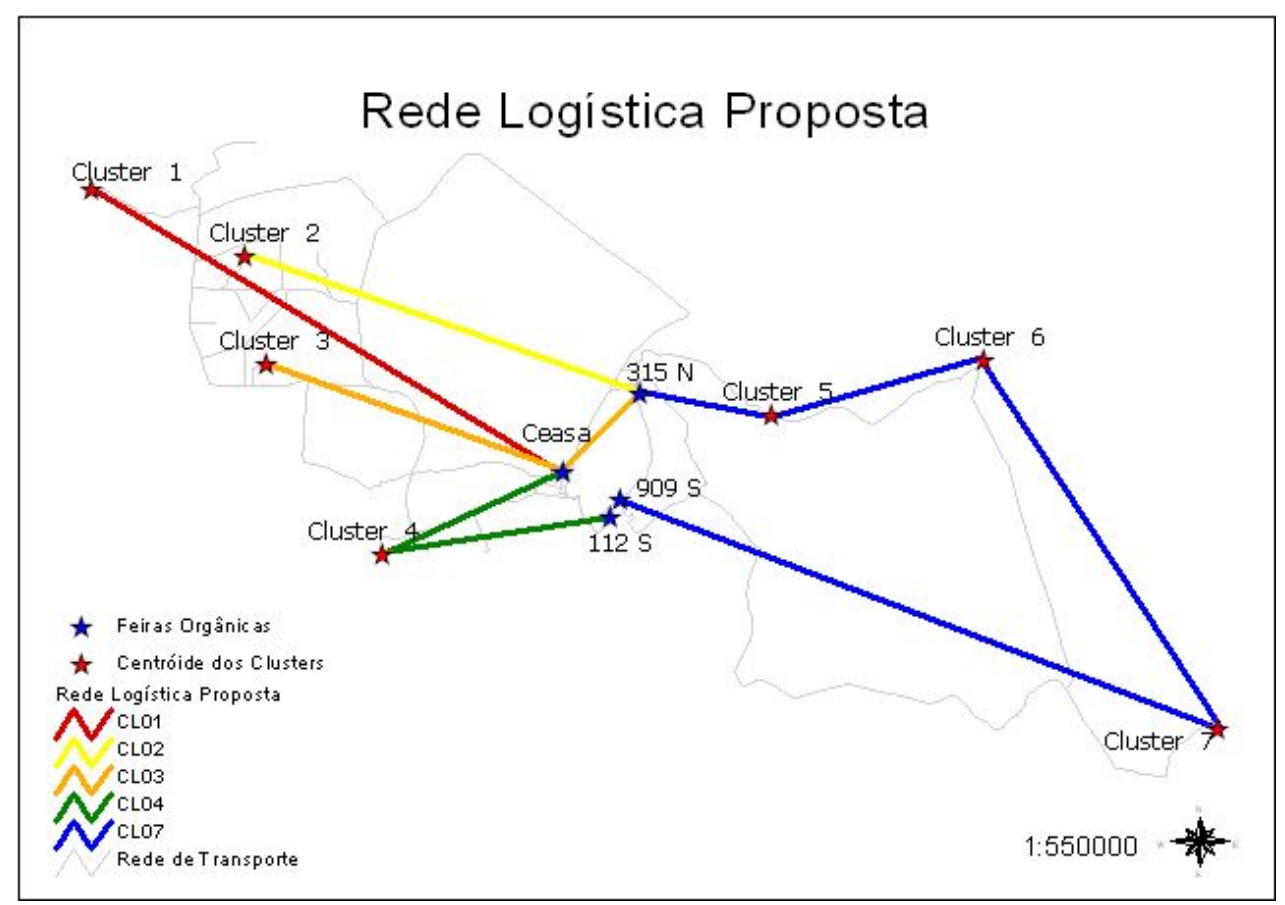

Figura 3. Rede logística proposta 
entes e de fácil manuseio, proporcionando resultados ótimos. O programa desenvolvido para a criação da matriz origem/destino também se mostrou uma ferramenta precisa. Este programa diminui o tempo necessário de processamento de informações, podendo trabalhar em um banco de dados maior. Sua principal qualidade é o uso de dados georreferenciados para o cálculo do menor caminho sobre uma rede viária digitalizada.

\section{REFERÊNCIAS BIBLIOGRÁFICAS}

Ballou, R. H. (2001) Gerenciamento da Cadeia de Suprimentos. Quarta edição. Porto Alegre: Bookman.

Bowersox, D. J. (2001) Logística Empresarial: O Processo de Integração da Cadeia de Suprimento. São Paulo: Atlas.

Guerra Neto, P. P. (2005) Modelo para o Planejamento do Sistema Logístico de Distribuição para associações de Produtores do Setor Hortigranjeiro: Estudo de Caso do Distrito Federal. Dissertação de Mestrado em Transportes, Publicação T.DM - 015/2005. Departamento de Engenharia Civil e Ambiental. Universidade de Brasília, Brasília, DF.

Economia e Transporte (2009) Disponível em $<$ http://economiaetransporte.com.br>.

EMATER - Empresa de Assistência Técnica e Extensão Rural. Disponível em < http://www.emater.df.gov.br > acessado em Maio de 2009.

EMBRAPA - Empresa Brasileira de Pesquisa Agropecuária. Disponível em: $<$ http://www.embrapa.br $>$.

IBD - Instituto Biodinâmico. Disponível em <http://www.ibd.com.br> acessado em junho de 2009.

JACK G.A.J; VAN DER VORST, A; BEULENS J.M. (2002). Identifying sources of uncertainty to generate supply chain redesign strategies. International Journal of Physical Distribution \& Logistics.

MUCKSTADT, J. A., et al. (2001).Guidelines for collaborative Supply Chain System Design and Operation. Information Systems Frontiers.

VAN DER VORST, J.G.A.J. (2000). Effective food supply chains: generating, modeling and evaluating supply chain scenarios.Tese (DoutoradoemAdministração) - Department of Social Sciences. Wageningen: Wageningen University. 